\title{
crónica de congresos
}

\author{
Andalucía Barroca: Congreso Internacional. \\ Antequera (Málaga), 17-21 de septiembre de 2007 \\ $M^{a}$ de los Ángeles Pazos Bernal \\ Conservadora de Patrimonio Histónico de la Junta de Andalucía
}

Adjetivos, como rico, complejo o variado, que suelen emplearse para la caracterización del Barroco, serán válidos también para referirse al conjunto de actos programados para tener desarrollo en los meses finales del año en curso y los iniciales del próximo, en el proyecto Andalucía Barroca 2007, que la Consejería de Cultura de la Junta de Andalucía celebra a impulso de la Dirección General de Bienes Culturales, cuyo titular, el historiador del Arte Jesús Romero Benítez, lo concibió desde su llegada al puesto en 2004.

Partiendo de la base de la importancia de Andalucía durante los siglos XVII y XVIII y de las definitorias huellas de carácter barroco que permanecen en nuestra tierra, se ha elaborado un completo programa, coordinado de cerca por el propio Director General, que implica, fundamentalmente, a los Servicios de Conservación y Restauración ${ }^{1}$ y de Investigación y Difusión ${ }^{2}$, en relación con las Delegaciones Provinciales, aunque también se haya hecho una revisión de la protección jurídica de los bienes seleccionados, para proceder a incluir los que aún no lo estaban en el Catálogo General del Patrimonio Histórico Andaluz.

Las acciones de restauración engloban la intervención en profundidad, tanto en la estructura arquitectónica como en sus elementos ornamentales y bienes muebles, en ocho inmuebles relevantes ${ }^{3} \mathrm{y}$ otros tantos órganos musicales ${ }^{4} \mathrm{y}$ retablos ${ }^{5}$.

Las de difusión incluyen la celebración de siete grandes exposiciones:

\footnotetext{
1 Del cual es jefe D. José Cuaresma Pardo y con el que han participado, de modo especial, D. Jesús Marín Fatuarte y $D^{a}$. Encarnación Díaz Chacón (Departamento de Bienes Muebles).

2 Bajo la jefatura de D. Carlos Sánchez de las Heras y con un equipo dirigido por $D^{a}$. Luz Pérez Iriarte, $D^{a}$ Salomé Rodrigo Vila y D. José Luis Romero Torres, respectivamente, jefa y asesores técnicos de Departamento de Difusión.

3 Los inmuebles seleccionados han sido las iglesias del antiguo convento de los Agustinos de Huécija (Almería), Parroquial del Sagrario (Catedral vieja o Iglesia de Santa Cruz) de Cádiz, de San Agustín de Córdoba, de Santo Domingo -Camarín de la Virgen del Rosario- de Granada, de Nuestra Señora del Reposo de Valverde del Camino (Huelva), la Ermita del Cristo del Llano de Baños de la Encina (Jaén), la Iglesia del Carmen de Antequera (Málaga), y la de los Descalzos de Écija (Sevilla).

${ }^{4}$ Los órganos restaurados son los existentes en las iglesias de la Encarnación de Vélez Rubio (Almería), San Lorenzo de Cádiz, San Hipólito de Córdoba, los Santos Justo y Pastor de Granada, Santiago Apóstol de Castaño del Robledo (Huelva), Santa María del Alcázar y San Andrés de Baeza (Jaén), San Sebastián de Antequera (Málaga) y la Iglesia de los Descalzos de Écija (Sevilla).

5 Los retablos restaurados dentro del programa se localizan en la Iglesia de la Asunción de Huércal-Overa (Almería), San Lorenzo de Cádiz, San Mateo de Lucena -Sagrario- (Córdoba), los Santos Justo y Pastor de Granada, Las Angustias de Ayamonte (Huelva), San Ildefonso de Jaén, Los Remedios de Antequera (Málaga) y Santa María de la Oliva de Lebrija (Sevilla).
} 


\section{Q: crónica de congresos}

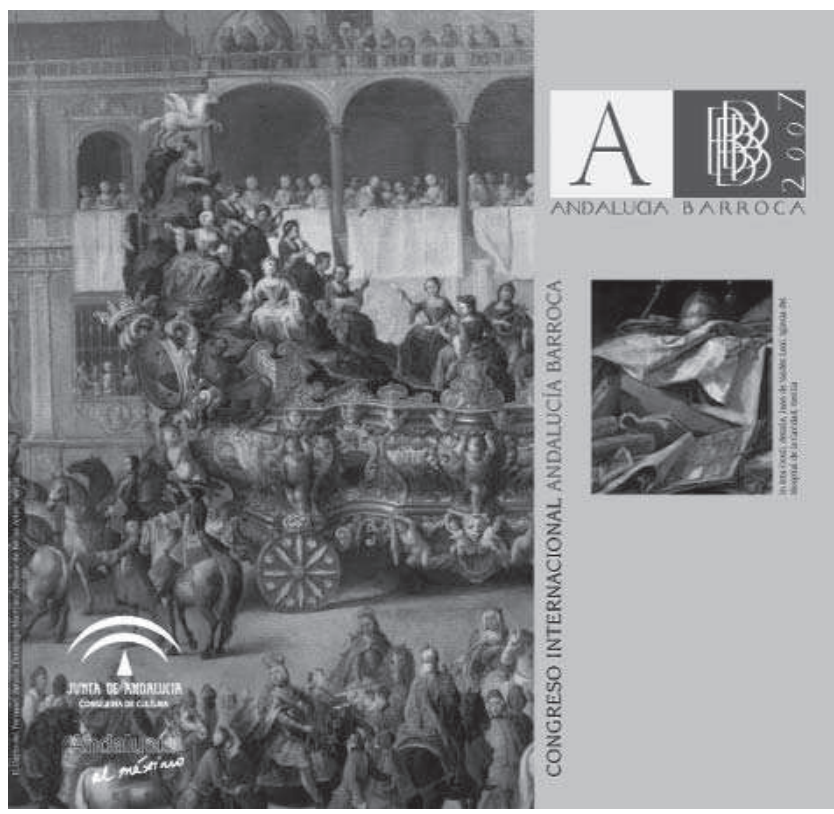

1. Cartel del congreso Andalucía Barroca.

"Roldana", en el Real Alcázar de Sevilla; "Andalucía Barroca. Exposición itinerante"; "Fiesta y Simulacro" en el Palacio Episcopal de Málaga; "El fulgor de la plata", en la Iglesia de San Agustín de Córdoba; "La imagen reflejada. Andalucía, espejo de Europa", en la Iglesia de Santa Cruz de Cádiz; "Teatro de grandezas", en el Hospital Real de Granada y "Antigüedad y excelencias", en el Museo de Bellas Artes de Sevilla. Éstas se acompañan de sus respectivos catálogos en los que se recogen no sólo los comentarios de las obras expuestas, sino estudios introductorios realizados por especialistas que, además del estado de la cuestión, aportan nuevas visiones y sugerencias en torno a cada tema.

Complemento a las tareas de difusión y puesta en valor, además de la producción de una serie de programas monográficos para la televisión autonómica andaluza, son los llamados "itinerarios temáticos", pensados para poner de relieve y facilitar la comprensión y la comparación de destacados elementos como torres, espadañas, palacios, retablos, yeserías, camarines u órganos musicales. Las 


\section{crónica de congresos}

Jornadas Europeas de Patrimonio tendrán en esta convocatoria 2007 el mismo argumento del Barroco.

Dentro de este entramado hay que entender la celebración en Antequera del Congreso Internacional, cuyos principales objetivos se cifran en "la revalorización del papel histórico de Andalucía, la puesta al día de sus estudios, el conocimiento de la contribución de sus creadores al panorama nacional y la difusión del patrimonio histórico que la sociedad barroca aportó a la cultura española y universal".

La centralidad geográfica de Antequera, nexo entre los principales caminos que comunican los extremos de Andalucía, y su relevancia durante los siglos citados, que le confirieron un marcado carácter que mantiene en su muy bien conservada arquitectura y patrimonio mueble, dan justificación a la elección de la ciudad malagueña como lugar de la celebración del Congreso.

Éste, bajo la coordinación científica del catedrático de Historia del Arte de la Universidad de Sevilla, D. Alfredo J. Morales Martínez, se estructuró en cuatro secciones a desarrollar, simultáneamente, en otras tantas sedes: Sección de Arte, Arquitectura y Urbanismo, presidida por D. Alberto Villar Movellán, en la Iglesia de San Juan de Dios; Sección de Historia demográfica, económica y social, presidida por D. Carlos Álvarez Santaló, en el Archivo Histórico Municipal; Sección de Literatura, Música y Fiesta, presidida por D. José Lara Garrido, en la Biblioteca Supramunicipal de San Zoilo y Sección de Ciencia, Filosofía y Religiosidad, presidida por D. José Antonio Pérez Tapias, en la Sala de exposiciones del Palacio Municipal.

En el marco barroco de la espléndida Iglesia del Carmen, consolidada en su estructura arquitectónica y restauradas sus pinturas y esculturas, tuvo lugar la sesión inaugural. Entre las intervenciones de la Excma. Sra. Consejera de Cultura, IImo. Sr. Alcalde de Antequera y Excmo. Sr. Presidente de la Junta de Andalucía, el Ilmo. Sr. Dr. D. Antonio Bonet Correa pronunció la conferencia "Andalucía Barroca, treinta años después", cuyo título alude a la publicación hace tres décadas en la editorial Polígrafa, de su famoso libro Andalucía Barroca. Arquitectura y Urbanismo. Las imágenes del mismo, gran aportación para reclamar la atención sobre el Barroco andaluz, su belleza y riqueza, se debieron al fotógrafo Xavier Miserachs, que Bonet recordó en entrañables episodios humanos.

Los actos inaugurales se completaron con la apertura al público en la Iglesia de Santa María de la exposición itinerante, que se tiene previsto que posteriormente se exhiba en Almería, Écija, Guadix, Huelva, Jaén, Jerez de la Frontera y Priego de Córdoba. Contando con los profesores D. Juan Luis Ravé Prieto y D. Pedro Respaldiza Lama, coordinadores del Gabinete Pedagógico de Bellas Artes de Sevilla como comisarios, constituye un esfuerzo de síntesis didáctica del fenómeno artístico Barroco contextualizándolo en el entorno físico, histórico, social e ideológico de

6 Las síntesis que adelantamos ahora, podrán ser objeto de conocimiento exacto y lectura reposada en las actas que próximamente se editarán. 


\section{crónica de congresos}

aquel momento. Los aspectos tratados (Arquitectura y Urbanismo, La integración de las artes, La mentalidad barroca, Andalucía puente entre Europa y América y Los focos artísticos), se valen de grandes paneles autoiluminados, de audiovisuales (EI Barroco, triunfo de la forma; Barroco arte total; El culto divino; Adoctrinar con imágenes; El Sancta Sanctorum; La etiqueta de palacio; llusionismo y plasticidad; Metamorfosis de un templo y La domus sacra) y de una selección de pinturas, esculturas, piezas de orfebrería y de otras artes suntuarias que irán incorporando obras propias de los lugares donde se presente la muestra.

Bajo la presidencia del Dr. D. Alberto Villar Movellán, se desarrolló la Sección de Historia del Arte, la que ha tenido una más numerosa asistencia y en la que centraremos nuestros comentarios dando algunas breves notas sobre el contenido de los discursos ${ }^{6}$. Los temas se introdujeron a base de ponencias, comunicaciones invitadas y comunicaciones presentadas por un relator.Las ponencias y las comunicaciones invitadas se eligieron considerando la especialidad de cada discente y la autoridad que la profundidad de la investigación a ella dedicada les concede, intentando que estuvieran representados los temas esenciales en sus distintos enfoques metodológicos.

El Dr. D. Pedro Galera Andreu ("La arquitectura en piedra. Tradición y acomodo a los nuevos gustos en Andalucía"), destacando el papel de los "cortistas", muchos de ellos vinculados con Jaén y la fábrica de su Catedral, aportó testimonios de la fortuna de la piedra frente a la idea de que la arquitectura barroca, por la búsqueda del movimiento y el ornamento, fue más bien de abañilería que de cantería, y apuntó que el prestigio de aquel material dio lugar a que en ciertas obras, pese a no estar ejecutadas en piedra, se pueda percibir un "modo estereotómico" (San Luis de los Franceses de Sevilla, Sagrario de la Iglesia de la Asunción y Capilla del Nazareno de la Iglesia de San Francisco de Priego, etc.).

El Dr. D. Teodoro Falcón Márquez ("La arquitectura andaluza a fines del Barroco"), recordó el tránsito desde la apoteosis exaltada de Leonardo de Figueroa y Hurtado Izquierdo, a través de la paulatina decantación decorativa de Bada o Diego Antonio Díaz, a la convivencia, en la segunda mitad del siglo XVIII, del Rococó y la arquitectura académica, de implantación desigual. Analizó, así mismo, ejemplos conservados de tipologías urbanas (plazas de las Nuevas Poblaciones de Sierra Morena, la de Archidona, la de Almería...) o arquitectónicas (ayuntamientos, casas palacio, iglesias, plazas de toros...).

La Dra. D $\mathrm{D}^{\mathrm{a}}$ Angeles Raya Raya ("Hurtado Izquierdo y su proyección en el arte andaluz del s. XVIII"), se centró en las obras culminantes del lucentino Francisco Hurtado Izquierdo: la sacristía de la Catedral de Córdoba, el sagrario de la Cartuja de Granada y el de la Cartuja de El Paular (Madrid), en los que encuentra circunstancias comunes como ser añadidos a construcciones preexistentes, la importancia de sus promotores, el contraste entre la sobriedad exterior y la exhuberancia interior, el sentido unitario de las artes que en ellos se manifiesta y la reiterada colaboración de otros artistas con Hurtado, como Pedro Duque Cornejo o Antonio Palomino.

El Dr. D José Ramón Soraluce Blond (“La arquitectura militar borbónica en 


\section{crónica de congresos}

Andalucía"), reivindicó a los ingenieros militares, organizados en tiempos de Felipe V (1711) por Jorge Próspero Verboon, las peculiaridades de su formación y método de trabajo, y su participación no sólo en obras de fortificación -muy importantes las de la ciudad de Cádiz-, sino también en fundamentales ejemplares de la primera arquitectura industrial, cual la Fábrica de Tabacos de Sevilla, cuya evolución, del concepto de cuartel que le otorgaba el proyecto de Ignacio de Sala (1728) al de palacio, con el de Sebastián van der Borcht (1750), analizó.

El Dr. D. Fernando Marías ("Vicente Acero. De Granada a Cádiz, de Málaga a Antequera") trató entre otras cosas de proyectos, añadiendo interesantes datos documentales inéditos sobre el de Vicente Acero para la Colegiata de Antequera -San Sebastián-, que adelanta a 1737, y donde se deseó hacer una catedral, superando la de la propia ciudad de Málaga, sobre el modelo retomado de la de Granada, ambiciosas ideas que no pasaron de serlo por el desvío de partidas económicas que conllevó la necesidad de paliar los efectos devastadores del terremoto de 1755.

El Dr. D. Germán Ramallo Asensio ("Intervenciones barrocas en las catedrales andaluzas"), partiendo de las normas y recomendaciones del Concilio de Trento, repasó sus consecuencias en elementos eucarísticos -sagrarios de Córdoba, Sevilla, Málaga, Cádiz, Granada, Guadix, Jaén- y tabernáculos -Córdoba, Almería, Jaén...-; la devoción a la Inmaculada, o el culto a las imágenes de aura milagrosa -Vírgenes de la Antigua de las catedrales de Sevilla y Granada y su instalación en los nuevos retablos-. Ponderó los estudios monográficos de las catedrales de Sevilla, Córdoba y Granada, los dos últimos de reciente aparición.

El Dr D. Joaquín Bérchez Gómez ("El Padre Pozzo y la arquitectura barroca andaluza"), puso de relieve la fuerte influencia, en todas las manifestaciones artísticas, de Andrea Pozzo a través de su obra teórica de amplísima difusión, ejemplificable en las deudas de Antonio Palomino, en todo el Palacio de San Telmo de Sevilla -desde el desarrollo de las cornisas sobre las columnas dado por Luca Cintora en la escalera del mismo a los fondos arquitectónicos de las pinturas de Domingo Martínez-, en Leonardo de Figueroa, en Vicente Acero o en Jerónimo Balbás.

El Dr. Duncan Th. Kinkead ("El mercado artístico de la pintura en Sevilla 1650-1699), abordó, con datos numéricos, estadísticos y gráficos, la situación de la ciudad en la que, en los cincuenta años considerados, están documentados más de 300 pintores y doradores, de los que sólo un 20 ó 25 \% debieron gozar una existencia holgada. Los que vivían en la prestigiosa zona de la Catedral fueron disminuyendo en número, mientras aumentaba el de los que lo hacían en la popular zona de la calle Feria, fenómeno que coincide con un aumento de los envíos a América, mercado que, pese a sus riesgos, era de interés porque aceptaba a mejor precio que aquí la producción mediocre. Aparte lo generado por el comercio con el Nuevo Mundo, el otro rasgo distintivo de Sevilla lo constituye la fundación de la Academia de Murillo, que se encontraba en el barrio de la Catedral, preguntándose Kinkead si los pintores de ésta y los que practicaban el mercado americano se vieron a sí mismos como miembros conscientemente antitéticos de la misma profesión. 


\section{crónica de congresos}

El Dr. D. Antonio Martínez Ripoll ('La pintura barroca andaluza, entre la singularidad estilística y la diversidad formal"), vino a defender la tesis de que en Andalucía la pintura de los siglos del Barroco "habló la misma lengua con distintos dialectos", entendiendo que no debe insistirse en la individualización de las escuelas cordobesa, malagueña o giennense; que en el granadino Juan de Sevilla se evidencian ecos de Zurbarán y Valdés Leal; que el pintor, natural de Jaén, Sebastián Martínez siguió a Alonso Cano, al igual que ocurrió con Miguel Manrique o Juan Niño de Guevara, que trabajaron en Málaga, por no insistir en lo que se hace en Granada, donde Cano se lleva a una verdadera clonación.

La Dra. Da Karin Hellwig ("Literatura artística en el Barroco andaluz"), revisó la literatura artística de los siglos del Barroco en la que ve una preponderancia de pintores escritores, cuyos textos, más que por abstractas elucubraciones académicas, se generaron para dar respuesta a cuestiones de índole práctica. Piensa que es poca la literatura jurídico-artística andaluza aún conocida, pero que ello puede cambiar en el futuro con nuevos hallazgos documentales.

El Dr. D. Luis Méndez Rodríguez ("Gremio y cultura artística en la pintura barroca sevillana"), centró su conferencia en una visión social del arte, en concreto, en el papel de los esclavos, que sirvieron de modelo o hicieron trabajos para sus señores y que, en ocasiones, fueron aprendices e incluso se examinaron, sin que los gremios, en la práctica, actuaran con completa intolerancia. Esta flexibilidad convivió con la teorización de la liberalidad y nobleza del arte de la pintura, creándose arquetipos como el del esclavo pintor que sólo asume tareas secundarias, del que es ejemplo conocido Juan de Pareja, esclavo de Velázquez.

El Dr. D. Alberto Villar Movellán ("Caudales y préstamos en la estética escultórica de la Andalucía barroca"), analizó la historiografía de la escultura barroca generada en el siglo XX en torno a las universidades de Sevilla y Granada. Si en la primera se produjo una amplísima investigación de los ricos fondos documentales conservados, en la segunda se creó la teoría general del desarrollo de ésta. Hizo la observación de que, aunque los contenidos de la escultura en ambos centros sean cuantitativamente muy diferentes, se ha tendido a equipararlos e, incluso, a fijar la preeminencia creativa de Granada sobre Sevilla.

Por otra parte, indagó en la originalidad de la interpretación del Crucificado en Rojas, sentando la importancia del modelo de Miguel Ángel y apuntando la posible influencia del realizado por Rodrigo Moreno para El Escorial, relativizando la influencia de Rojas sobre Montañés y apuntando la prelación del Cristo de la Clemencia sobre el de la Sacristía de la Catedral de Granada de los hermanos García, y la función de puente que estos artistas pudieron ejercer entre la estética de Montañés y la de Mesa.

El Dr. D. Domingo Sánchez-Mesa Martín (“Teatralidad y escenografía en el retablo barroco andaluz") hizo un recordatorio de las importantísimas aportaciones de la historiografía del siglo XX, numerosas en su segunda mitad, a la documentación, clasificación y valoración de la retablística de los siglos XVII y XVIII en las pro- 


\section{Q: crónica de congresos}

vincias andaluzas, propugnando la necesidad de nuevas lecturas desde el punto de vista de la iconografía; los requerimientos de la liturgia del momento; la espacialidad de los interiores arquitectónicos, a los que aquellos se incorporaron en gran número, ó la sacralización de los espacios públicos por las portadas-retablo.

El Dr. D. Pavel Stepanek ("El arte barroco andaluz en las colecciones reales de Bohemia"), incidió en las claves de los contactos entre Andalucía y Bohemia que, aparte de otras relaciones, como las comerciales - existencia de datos de la venta de cristal de Bohemia en Sevilla y Cádiz; uso del cristal azul molido en pinturas americanas-, se cifran, fundamentalmente, en las monarquías reinantes, pertenecientes a la Casa de Austria, el compartido catolicismo y el coleccionismo.

El Dr. D. Benito Navarrete Prieto ("La estampa como modelo en el Barroco andaluz"), ofreció una nueva demostración del usual método de trabajo que suponía el empleo de las fuentes icónicas grabadas en el arte pictórico, escultórico y en la retablística, tanto para composiciones generales como para la resolución de toda clase de detalles, dando ejemplos de diferentes artistas (Zurbarán, Antonio del Castillo, Murillo, Martínez Montañés, Sánchez Cotán, La Roldana...) a los que "aprovecharon" -en palabras de Antonio Palomino- las estampas y las imágenes de los tratados, reinterpretadas o sólo traspuestas según la capacidad del autor.

EI Dr. D. Jesús Rivas Carmona ("La significación de los mármoles del Barroco andaluz"), ahondó en las connotaciones del uso de los mármoles en Andalucía, que, empleados abundantemente, al igual que en Italia, dan a nuestro Barroco carácter cosmopolita. Con estas piedras y sus cualidades de brillo y color, se lograban con efectividad suntuosos efectos en aspectos, tan esenciales para el contrarreformismo, como el culto eucarístico -analizando, así, desde el retablo de la Catedral de Córdoba y el preciosismo de los veteados y embutidos de su tabernáculo, hasta los templetes trazados por Hurtado Izquierdo para la Orden Cartuja-, ó mariano, que generó uno de los principales capítulos de la marmolería andaluza en trascoros, retablos y camarines.

El Dr. D. Gabriele Finaldi ("Repercusiones de la pintura barroca andaluza en Inglaterra") dirigió su discurso a las reacciones suscitadas por la adquisición, en 1853, para la Galería Nacional de Londres del San Francisco en éxtasis de Zurbarán, que fue adjetivado de "pequeño, negro y repulsivo cuadro". En todo caso, la llegada de la pintura a Inglaterra y la propia polémica que generó, ayudaron a la difusión del conocimiento allí de Francisco de Zurbarán, registrándose una literatura generada por los ingleses que visitan España, entre ellos Richard Ford, que va situando al pintor como artista importante además del, para esa fecha ya conocido, Bartolomé Esteban Murillo.

La Dra. $D^{a} M^{a}$ Teresa Dabrio González ("Tipología y ornamento en las cruces procesionales del Barroco cordobés"), destacó las cruces procesionales entre la variada tipología que se produjo en los activos talleres de platería cordobeses. Los primeros ejemplares conservados, como sucede en otros núcleos andaluces, reflejan la dependencia estética de los modelos surgidos de maestros como Francisco 


\section{Q: crónica de congresos}

Merino y Francisco de Alfaro, aunque con mayor gusto por lo ornamental, según se aprecia en el ejemplar de la Catedral de Córdoba, obra hecha a expensas del obispo fray Diego de Mardones por Pedro Sánchez de Luque entre 1620 y 1625.

La segunda mitad del Seiscientos supone una depuración de formas y ornamentos, patente en piezas como la Cruz del Monasterio de la Encarnación y la de la parroquial de Posadas. A mediados del siglo XVIII, Damián de Castro renueva la tipología y reaviva el gusto por el ornamento, creando cruces de extraordinaria calidad, como las de Santaella y Villa del Río, que se convertirán en prototipos seguidos por los talleres cordobeses de su tiempo.

El Dr. D. Alfredo J. Morales Martínez ("Yeserías fingidas en la Sevilla de finales del Seiscientos"), abordó el tema ornamental de los interiores arquitectónicos mediante pinturas simulando yeserías. Las de la Iglesia de Santa María la Blanca de Sevilla, concluidas en 1665 , las considera el precedente más directo del progresivo abandono de las labores en yeso en beneficio de los ciclos pictóricos, en los que se reproducen con precisión las formas plásticas de las yeserías.

Así ocurrió en el antepresbiterio de la Iglesia del Hospital de la Santa Caridad, en el presbiterio y coro de la Iglesia del Convento de San Clemente y en algunos sectores de la Iglesia del Hospital de los Venerables. En todos ellos intervino Juan de Valdés Leal ayudado por su hijo Lucas Valdés, quien continuaría la tradición durante las primeras décadas del siglo XVIII. Es el caso de su trabajo en la Iglesia del Convento de San Pablo, actual parroquia de la Magdalena. Prueba de la generalización de las yeserías fingidas es también la decoración del presbiterio de la Iglesia del Convento de Santa María de Jesús, por José López Chico.

Se ha aplicado al Congreso la fórmula del "relator", con misión de sintetizar las aportaciones de las comunicaciones recibidas, rentabilizando con su acción los tiempos concedidos a éstas. El Dr. D. Cristóbal Belda Navarro, catedrático de Historia del Arte de la Universidad de Murcia, ejerció su tarea de modo ejemplar, haciendo la síntesis de las comunicaciones, a la par que vertiendo su erudición en las glosas de cada una de ellas. Las apostillas y excursus que se permitió el relator, ampliaron, sin duda, la visión de los temas tratados por los comunicantes, dando espectro doctoral a los asuntos, interesantes todos ellos y por lo cual seleccionados ${ }^{7}$.

El programa del Congreso incluía visitas a la propia Antequera, a Priego de

7 Las comunicaciones seleccionadas en la Sección de Arte, arquitectura y urbanismo fueron: ANGUITA HERRADOR, Rosario: "Apuntes acerca de la situación de los plateros y la platería en la segunda mitad del siglo XVIII"; GARCÍA ALCÁZAR, Silvia: "Barroco y Romanticismo: concepciones del arte moderno durante el siglo XIX"; GONZÁLEZ LUQUE, Francisco: "Influencias sevillanas e italianas en la escultura barroca de EI siglo XIX"; GONZALEZ LUQUE, Francisco: "Influencias sevillanas e italianas en la escultura barroca de EI su obrador"; LORENZO LIMA, Juan Alejandro: "Constantes del comercio artístico entre Canarias y Andalucía durante el siglo XVIII"; MALO LARA, Lina: "Juan del Castillo, maestro pintor del Barroco sevillano. Revisión y aportaciones"; PALENCIA CEREZO: José Ma: Sebastián Martínez y el Apostolado del Palacio Episcopal de Córdoba"; PÉREZ RUFI, M ${ }^{a}$ Isabel: "La influencia italiana en la joyería andaluza del siglo XVIII. Notas comparativas entre una colección de dibujos italianos y el Segundo Libro de Joyas de Sevilla"; RAMOS FRENDO, Eva Ma: "El coleccionismo en la Andalucía Barroca"; SANTOS MÁRQUEZ, Antonio Joaquín: "José 


\section{crónica de congresos}

Córdoba y a Écija, que comparten la condición de ser ciudades medias de gran vitalidad actual, con un pasado en el que los siglos del Barroco les imprimieron sus señas de identidad más fuertes. Tales visitas ${ }^{8}$ fueron excepcionales porque para ellas se gestionó el acceso a lugares que de forma habitual no están franqueados al público.

La tarde del miércoles día 19 se presentó con dos opciones de gran interés, lamentablemente sólo compatibles con dificultad: la visita a Priego de Córdoba, y la inauguración, en el Palacio Episcopal de Málaga, de la exposición Fiesta y Simulacro, de la que son comisarias las doctoras Da. Rosario Camacho Martínez y $D^{a}$. Reyes Escalera Pérez, de la Universidad de Málaga. Es esta muestra, efímera, en la esencia de lo evocado, una seria y feliz demostración artística, histórica y sociológica, del pensamiento y el sentimiento de los siglos XVII y XVIII y sus pervivencias, donde lo culto, de gran elaboración, y lo popular, también de profundas raíces, se ponen de manifiesto en un inteligente discurso, capaz de mantener el interés y la emoción, pese a lo arduo para los no especialistas de parte del material expuesto, consistente en libros y grabados, testimoniales de celebraciones religiosas ó civiles con motivos tan antitéticos, como exequias religiosas y entradas reales.

Finalmente, cabe mencionar que, al hilo del Congreso, se celebraron dos conciertos musicales. En la Colegiata de San Sebastián se reestrenó su órgano restaurado por los técnicos dirigidos por Gerhrard Grenzing ${ }^{9}$ y en la Iglesia de Los Remedios actuó el Royal Brass Quintet.

En suma, un cúmulo de brillantes acontecimientos que, desde miradas intelectuales, esperan acrecer no sólo la reflexión erudita sino la comprensión general de algunos episodios de especial significación de nuestro pasado y su valoración patrimonial por la sociedad.

Portillo (h. 1650-1685), un platero del Barroco andaluz"; ROMERO TORRES, José Luis: "Renovación estética de las catedrales andaluzas en la década de 1650".

8 Guiadas por el IImo. Sr. D. Jesús Romero Benítez en Antequera, las historiadoras del arte Da Soledad Jiménez Barreras y Da Rosario Vega Reyes en Priego de Córdoba y el Dr. D. Gerardo García León en Écija.

${ }^{9}$ Hay programado un ciclo de varios conciertos en cada uno de los órganos restaurados. 